Systematic Review

\title{
Obesity and Stunting in Childhood. Do Grandparents Play A Role? A Systematic Review
}

\author{
Rizki Agustin Purwaningtyas, Ardila Lailatul Barik and Dwi Astuti
}

Faculty of Nursing, Universitas Airlangga, Surabaya, Indonesia

\begin{abstract}
Introduction: Obesity and stunting in childhood has become one of the greatest global health challenges. The impact of this issue is serious and lasting for individuals, their families, communities and countries. Most of the studies on child weight status have only focused on the mother as the primary caregiver, whereas the role and influence of the grandparents has received less attention. Grandparent-provided child care has become a trend in many countries, with reported rates of approximately $40 \%$ to $58 \%$. The objective of this systematic review was to analyze whether children become stunted or obese when they are cared for by their grandparents.

Methods: The methodological search of the literature was conducted using Scopus, Science Direct, PubMed, Pro Quest and ResearchGate, and it was undertaken using PRISMA guidelines. The search identified 1803 papers and 135 full-text articles were screened for eligibility. Finally, 15 met the inclusion criteria. The keyword chain was as follows: ("obesity" OR "stunting") AND ("children") AND ("grandparents").

Results: As grandparents take on increasingly responsible roles in the lives of their grandchildren, there is an influence on the higher risk of child obesity rather than stunting.

Conclusion: In future, nurses should target not only the mother but also the grandparents to control their child's health, especially when related to their weight status.
\end{abstract}

\section{ARTICLE HISTORY}

Received: Dec 26, 2019

Accepted: Dec 31, 2019

\section{KEYWORDS}

obesity; stunting; children; grandparents

\section{CONTACT}

Rizki Agustin Purwaningtyas $\triangle$ rizki.agustin.purwaningtyas2018@fkp.unair.ac.id $\equiv$ Faculty of Nursing, Universitas Airlangga, Surabaya, Indonesia

Cite this as: Purwaningtyas, R. A., Barik, A. L., \& Astuti, D. (2019). Obesity and Stunting in Childhood. Do Grandparents Play A Role? A Systematic Review.Jurnal Ners, 14(3si), 71-75. doi:http://dx.doi.org/10.20473/in.v14i3(si).16986

\section{INTRODUCTION}

The increasing rate of overweight and obesity is faced in many developing countries, though undernutrition is still prevalent in these countries as well. This coexistence of overnutrition and undernutrition is often referred to as the double burden of malnutrition (Sekiyama, Jiang, Gunawan, Dewanti, \& Honda, 2015). If immediate action is not taken, then countless numbers of people will develop an array of serious, chronic and costly health disorders. Unlike undernutrition, overnutrition has multifaceted, clustered effects that result in disability and disease, which creates a significant burden for both families and the healthcare system. Because of their smaller stature, children who grow up with a state of malnutrition are at a greater risk of being overweight (weight related to height) as adults (Walrod et al., 2018).

Most of the studies on child weight status have only focused on the mother as the primary caregiver. Little rigorous research has been performed that focuses primarily on the influence of the grandparents on child dietary intake and weight status. The trend towards grandparent-provided child care applies internationally, with reported rates of grandparental caregiving being approximately from 40\% (Geurts, Van Tilburg, Poortman, \& Dykstra, 2015) and up to 58\% (Bordone, Arpino, \& Aassve, 2015). In 2010, 66.5\% of mothers were engaged in some level of employment, and with this, there has been an increasing call on the grandparents to assist with 'informal' childcare (Wellard, 2011). As the grandparents take on increasingly responsible roles in the lives of their grandchildren, it could reasonably 


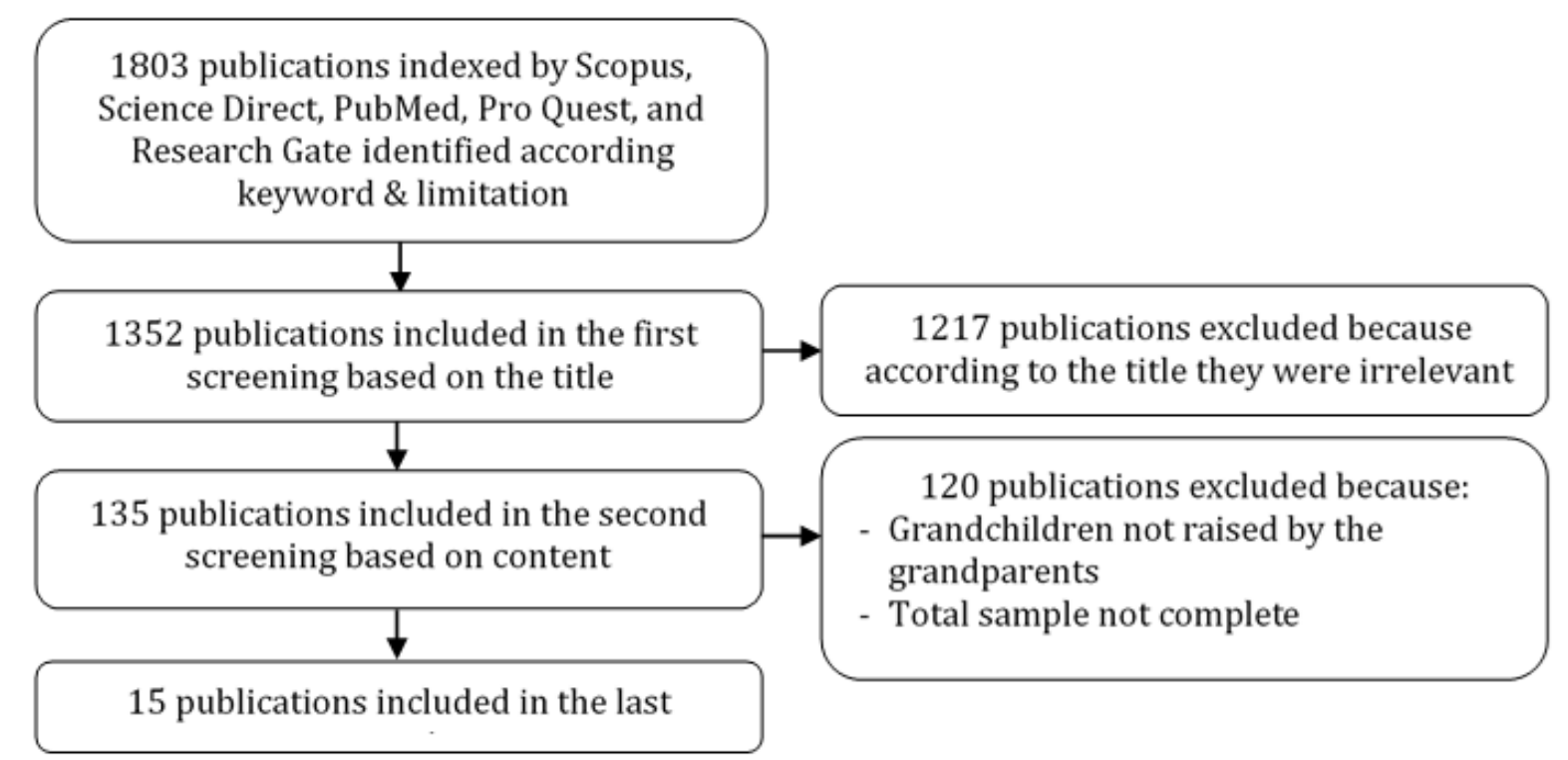

Figure 1. Results and selection procedure

be assumed that their attitudes, beliefs and feeding practices may have a similarly significant influence on child dietary intake and weight status (Young, Duncanson, \& Burrows, 2018).

The objective of this systematic review was to analyze whether children become stunted or obese when they are cared for by their grandparents. Who is affected by the grandparent being the caregiver more - is it the boys or girls? How old is the child when their weight status is influenced by the grandparent's provided care? Who is the most common caregiver of the child; the grandparents only or the grandparents with others?

\section{MATERIALS AND METHODS}

The study began with a systematic literature search. The next step was to determine the keyword chains, and two components were used as the search terms to identify studies on 'Obesity and Stunting in Childhood' and 'Do The Grandparents Play A Role?': (1) grandparents and stunting, (2) grandparents and obesity. The results of this keyword formulation were used to find the relevant literature in 5 databases (Scopus, Science Direct, PubMed, Pro Quest, and Research Gate). The keyword chain was as follows: ("stunting or obesity") AND ("grandparents").

The first screening was based on the titles and abstracts. At this stage, the publication was considered to be potentially relevant if the title and abstract had a link to the review topic. Articles that met the inclusion criteria were selected for all content. The selected articles totaled 15. This type of analysis requires themes that are relevant to the purpose of the review. The theme groups used for the review and for this form of analysis were: (1) grandparents only or with another caregiver, (2) age of children, (3) gender, and (4) body weight. The limitation regarding publication year was that it had to be between 2015 and now. The only type of document selected was articles. The search results concluded on February 20 $0^{\text {th }}, 2019$ with a keyword chain and limitation criteria, and it obtained 1803 articles. Various inclusion and exclusion criteria were applied; the publications must be in English, the number of qualitative research samples had to be $>12$ and quantitative $>100$ and the research sample must be children aged above or below the age of 5 who were cared for by their grandparents. Articles that were only a trial and that did not contain written results were not included.

\section{RESULTS}

The search results used a predefined keyword chain that generated 1803 publications. The screening results have been presented in the figure below. In the first screening, 1352 publications were excluded after reading the titles based on the inclusion / exclusion criteria. In total, 135 publications were included in the second screening. For the second screening, the publication was downloaded. Of the 135 articles, 120 publications were excluded after reading the full text. The reasons for exclusion were: (1) grandchild are not cared for by the grandparents; (2) the number of samples not meeting the minimum; (3) a combination of the reasons above. After the second screening, 15 publications were selected for the systematic review. A detailed description of the publications has been presented in the Appendix.

The results of the review illustrate that as many as $73.3 \%$ have excess weight or are obese when they are cared for by their grandparents. Obese children who were cared for by their grandparents were under the age of 5 years making up a percentage of $40.0 \%$ while the children who were stunted made up only $26.7 \%$. 
Table 1. Description of the relevant publications according to the analysis criteria

\begin{tabular}{|c|c|c|c|}
\hline Classification & Sub Category & Total (\%) & Reference index (appendix 1)* \\
\hline \multirow[t]{5}{*}{ Publication year } & 2019 & $2(13.3)$ & 4,15 \\
\hline & 2018 & $7(46.7)$ & $1,2,3,7,8,11,14$ \\
\hline & 2017 & $3(20.0)$ & $5,10,13$ \\
\hline & 2016 & $1(6.7)$ & 6 \\
\hline & 2015 & $2(13.3)$ & 9,12 \\
\hline \multirow[t]{2}{*}{ Body weight } & Obesity & $11(73.3)$ & $1,3,4,8,9,10,11,12,13,14,15$ \\
\hline & Stunting & $4(26.7)$ & $2,5,6,7$ \\
\hline Children's age & Children aged $<5$ years & $5(33.3)$ & $8,9,11,13,14$ \\
\hline \multirow[t]{2}{*}{ Obesity } & Children aged $>5$ years & $6(40.0)$ & $1,3,4,10,12,15$ \\
\hline & Children aged $<5$ years & $4(26.7)$ & $2,5,6,7$ \\
\hline Stunting & Children aged $>5$ years & 0 & 0 \\
\hline Children's sex & Boy & $1(6.7)$ & 3 \\
\hline \multirow{4}{*}{ Obesity } & Girls & $0(0)$ & 0 \\
\hline & Both boy and girl & $3(20.0)$ & $1,10,15$ \\
\hline & Not mentioned & 7 (46.7) & $4,8,9,11,12,13,14$ \\
\hline & Boy & $1(6.7)$ & 2 \\
\hline \multirow[t]{3}{*}{ Stunting } & Girls & $1(6.7)$ & 6 \\
\hline & Both boy and girl & $0(0)$ & 0 \\
\hline & Not mentioned & $2(6.7)$ & 5,7 \\
\hline Caregiver & Grandparents & $6(40.0)$ & $1,3,4,8,10,15$ \\
\hline \multirow[t]{2}{*}{ Obesity } & Grandparents and others & $5(33.3)$ & $9,11,12,13,14$ \\
\hline & Grandparents & $1(6.7)$ & 2 \\
\hline Stunting & Grandparents and others & $3(20.0)$ & $5,6,7$ \\
\hline Age of caregiver & $<45$ years old & $0(0)$ & 0 \\
\hline \multirow[t]{2}{*}{ Obesity } & $>45$ years old & $1(6.7)$ & 3 \\
\hline & Not mentioned & $10(66.7)$ & $1,4,8,9,10,11,12,13,14,15$ \\
\hline \multirow[t]{3}{*}{ Stunting } & $<45$ years old & $0(0)$ & 0 \\
\hline & $>45$ years old & $2(13.3)$ & 2,7 \\
\hline & Not mentioned & $2(13.3)$ & 5,6 \\
\hline Sex of caregiver & Male & $0(0)$ & 0 \\
\hline \multirow[t]{2}{*}{ Obesity } & Female & $3(20.0)$ & $3,11,14$ \\
\hline & Not mentioned & 8 & $1,4,8.9,10,12,13,15$ \\
\hline \multirow[t]{3}{*}{ Stunting } & Male & $0(0)$ & 0 \\
\hline & Female & $3(20.0)$ & $2,5,7$ \\
\hline & Not mentioned & 1 & 6 \\
\hline
\end{tabular}

*complete appendix available on supplementary file

However, the results of the reviewed journals did not specifically explain the sex of children who were potentially obese or stunted; $40.0 \%$ of children who were cared for by their grandparents were obese while the children who experienced stunting when cared for by their grandparents made up only $20.0 \%$. The age of the caregivers that potentially influence their grandchildren to be obese was not specifically mentioned with a percentage of $66.7 \%$ while $13.3 \%$ of children potentially faced stunting when cared for by a caregiver aged more than 45 years old. By $53.3 \%$, the sex of the caregiver in the articles that were reviewed was not mention specifically.

\section{DISCUSSION}

This systematic review discussed the relation between malnutrition (stunting and obesity) and being cared for by their grandparents. Fifteen articles have been reviewed. The limitations of this study are that most of the studies didn't mention the age and gender of the grandparents. So the researcher didn't know how old the grandparents who cared for their children were and if they were a grandfather or grandmother.
The results of this review show that the percentage of obesity is more often than the incidence of stunting in children who were cared for by their grandparents. Obesity can occur because the energy intake from food exceeds the children's energy requirements. Grandparents have inappropriate perceptions related to nutrition in children (they assume that obese children are healthier and well cared for). Grandparents usually over-indulge their grandchildren including overfeeding them. Children thus consume more unhealthy snack and sugar-added drinks (UNICEF; WHO; The World Bank, 2015; (Li, Adab, \& Cheng, 2015).

The classification of child age in this study showed that children who were more than five years old had the potential of facing obesity. This finding is the same as the research conducted by (Lau, $\mathrm{Au}, \mathrm{Chao}$, Elbaar, $\&$ Tse, 2018) that showed that school-age ( $>5$ years old) and adolescent children with grandparental care were more likely to be overweight and that there was no increased risk of being overweight or obese in the preschool group ( $<5$ years old)(Lau et al., 2018).

The study found that most of the articles did not mention the gender of the child who had the potential to be obese or stunted. This finding is in line with the 
research (Maruf, Aronu, Chukwuegbu, \& Aronu, 2013) stating that there was no gender difference in the prevalence of obesity from childhood through to adolescence. In conclusion, BMI is larger in males in early childhood but larger in females during adolescence. Another study(Lau et al., 2018) also showed that there was no significant association between the sex of the child and having their grandparents as caretakers.

Review's classification by the caregiver indicated that grandparent was the most caregiver who influence children become obesity. This is in accordance with a previous study ( $\mathrm{He}, \mathrm{Li}$, \& Wang, 2018) that showed that the coresidence of grandparents can affect childhood weight outcomes. First, grandparents, especially in rural areas, often consider overweight babies as being healthy and lean babies as malnourished, as they lack health-related (particularly nutrition-related) knowledge. Therefore, they tend to overfeed their grandchildren. Second, most Chinese grandparents experienced low weight, malnutrition, food shortages, physical hardships and other deprivation in their early lives (Li, Adab, \& Cheng, 2015).

Most of the articles in this review did not mention the age of the caregiver. Based on a previous study, this review suggests that the grandparents should not be too young. A possible explanation is that when the grandparents are very young and still reproductive themselves, they have to put their energy into running their own households and they have less possibility to take care of their grandchildren (Schrijner \& Smits, 2018).

This review foud that most of the articles that were reviewed did not mention the specific gender of the grandparents. But one study(Schrijner \& Smits, 2018b) showed the result that grandfathers are less involved in household work and in helping their daughters(-in-law) with caring and feeding tasks. Compared to the grandmothers, grandfathers are probably more focused on the future achievements of their grandchildren in society. This does not mean that the grandfathers are not important to their grandchildren but their role might differ from that of the grandmother (Schrijner \& Smits, 2018).

\section{CONCLUSION}

This systematic review found that co-residence of grandparents can affect children obesity. Community health nursing must include the grandparents and other caregivers of the child when it comes to giving them information such as education about how to keep their children body weight in normal range.

\section{REFERENCES}

Ban, L., Guo, S., Scherpbier, R. W., Wang, X., Zhou, H., \& Tata, L. J. (2017). Child feeding and stunting prevalence in left-behind children: a descriptive analysis of data from a central and western Chinese population. International Journal of Public
Health, $62(1)$ $143-151$ https://doi.org/10.1007/s00038-016-0844-6

Bell, L. K., Perry, R. A., \& Prichard, I. (2018). Exploring Grandparents' Roles in Young Children's Lifestyle Behaviors and the Prevention of Childhood Obesity: An Australian Perspective. Journal of Nutrition Education and Behavior, 50(5), 516-521. https://doi.org/10.1016/j.jneb.2017.12.007

Bordone, V., Arpino, B., \& Aassve, A. (2015). Patterns of grandparental child care across Europe: the role of the policy context and working mothers' need. Ageing and Society, 37(4), 845-873. https://doi.org/10.1017/s0144686x1600009x

Finlay, J. E., Fink, G., McCoy, D. C., Tavárez, L. C., Chai, J., Danaei, G., ... Fawzi, M. C. S. (2016). Stunting risk of orphans by caregiver and living arrangement in low-income and middle-income countries. Journal of Epidemiology and Community Health, 70(8), 784-790. https://doi.org/10.1136/jech-2015206346

Geurts, T., Van Tilburg, T., Poortman, A. R., \& Dykstra, P. A. (2015). Child care by grandparents: Changes between 1992 and 2006. Ageing and Society, $35(6)$, 1318-1334. https://doi.org/10.1017/S0144686X14000270

He, Q., Li, X., \& Wang, R. (2018). Economics and Human Biology Childhood obesity in China: Does grandparents ' coresidence matter? Economics and Human Biology, 29, 56-63. https://doi.org/10.1016/j.ehb.2018.02.001

Ikeda, N., Fuse, K., \& Nishi, N. (2017). Changes in the effects of living with no siblings or living with grandparents on overweight and obesity in children: Results from a national cohort study in Japan. PLoS ONE, 12(4), 1-12. https://doi.org/10.1371/journal.pone.0175726

Jongenelis, M. I., Talati, Z., Morley, B., \& Pratt, I. S. (2019). The role of grandparents as providers of food to their grandchildren. Appetite, 134, 78-85. https://doi.org/10.1016/j.appet.2018.12.022

Lau, J. D., Au, L. Y., Chao, E., Elbaar, L., \& Tse, R. (2018). The Association of Grandparent Care with Childhood Overweight and Obesity in Chinese American Families. Childhood Obesity, 15(1), 1420. https://doi.org/10.1089/chi.2018.0113

Li, B., Adab, P., \& Cheng, K. K. (2015a). The role of grandparents in childhood obesity in China evidence from a mixed methods study. International Journal of Behavioral Nutrition and Physical Activity, 12(1), 1-9. https://doi.org/10.1186/s12966-015-0251-z

Li, B., Adab, P., \& Cheng, K. K. (2015b). The role of grandparents in childhood obesity in China evidence from a mixed methods study. International Journal of Behavioral Nutrition and Physical Activity, 12(1). https://doi.org/10.1186/s12966-015-0251-z

Li, Q., Liang, F., Liang, W., Zhang, J., Niu, M., \& Han, Y. (2017). The Influence of Different Caregivers on Infant Growth and Development in China. Frontiers in Pediatrics, 5(November), 1-7. https://doi.org/10.3389/fped.2017.00243 
Lidgate, E. D., Li, B., \& Lindenmeyer, A. (2018). A qualitative insight into informal childcare and childhood obesity in children aged $0-5$ years in the UK. BMC Public Health, 18(1), 1229. https://doi.org/10.1186/s12889-018-6131-0

Lindberg, L., Ek, A., Nyman, J., Marcus, C., Ulijaszek, S., \& Nowicka, P. (2016). Low grandparental social support combined with low parental socioeconomic status is closely associated with obesity in preschool-aged children: a pilot study. Pediatric Obesity, 11(4), 313-316. https://doi.org/10.1111/ijpo.12049

Maruf, F. A., Aronu, U., Chukwuegbu, K., \& Aronu, A. E. (2013). Influence of gender on prevalence of overweight and obesity in Nigerian schoolchildren and adolescents. Tanzania Journal of Health Research, 15(4), 1-6. https://doi.org/10.4314/thrb.v15i4.6

Metbulut, A. P., Özmert, E. N., Teksam, O., \& Yurdakök, K. (2018). A comparison between the feeding practices of parents and grandparents. European Journal of Pediatrics, 177(12), 1785-1794. https://doi.org/10.1007/s00431-018-3244-5

Min, J., Zhao, Y., Slivka, L., \& Wang, Y. (2018). Double burden of diseases worldwide: coexistence of undernutrition and overnutrition-related noncommunicable chronic diseases. (January), 49-61. https://doi.org/10.1111/obr.12605

Schrijner, S., \& Smits, J. (2018a). Grandmothers and Children's Schooling in Sub-Saharan Africa. Human Nature, 29(1), 65-89. https://doi.org/10.1007/s12110-017-9306-y

Schrijner, S., \& Smits, J. (2018b). Grandparents and Children's stunting in sub-Saharan Africa. Social Science and Medicine, 205, 90-98. https://doi.org/10.1016/j.socscimed.2018.03.03 7
Sekiyama, M., Jiang, H. W., Gunawan, B., Dewanti, L., \& Honda, R. (2015). Double Burden of Malnutrition in Rural West Java: Household-Level Analysis for Father-Child and Mother-Child Pairs and the Association with Dietary Intake. 8376-8391. https://doi.org/10.3390/nu7105399

UNICEF; WHO; The World Bank. (2015). Levels and trends in child malnutrition. UNICEF-WHO-World Bank Group Joint Child Malnutrition Estimates, 4. https://doi.org/10.1016/S0266-6138(96)900674

Walrod, J., Seccareccia, E., Sarmiento, I., Pimentel, J. P., Misra, S., Morales, J., ... Andersson, N. (2018). Community factors associated with stunting, overweight and food insecurity: a communitybased mixed- method study in four Andean indigenous communities in Ecuador. 1-11. https://doi.org/10.1136/bmjopen-2017-020760

Wellard, S. (2011). Doing it all?: grandparents, childcare and employment: an analysis of British Social Attitudes survey data from 1998 and 2009. (December).

Young, K. G., Duncanson, K., \& Burrows, T. (2018). Influence of grandparents on the dietary intake of their 2 - 12-year-old grandchildren : A systematic review. Nutrition \& Dietics: The Journal of the Dietitian Association of Australia, 75(3), 291-306. https://doi.org/10.1111/1747-0080.12411

Zhang, Y., Ji, M., Zou, J., Yuan, T., Deng, J., Yang, L., ... Lin, Q. (2018). Effect of a conditional cash transfer program on nutritional knowledge and food practices among caregivers of 3-5-year-old leftbehind children in the rural Hunan province. International Journal of Environmental Research and Public Health, 15(3), 1-13. https://doi.org/10.3390/ijerph15030525 